Jurnal Keperawatan Silampari

Volume 4, Nomor 1, Desember 2020

e-ISSN: 2581-1975

p-ISSN: 2597-7482

DOI: https://doi.org/10.31539/jks.v4i1.1773

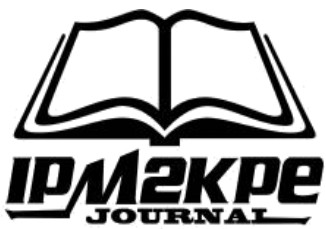

\title{
PENYEMBUHAN LUKA GRADE 2 PADA PASIEN DIABETES MELLITUS DENGAN MODERN DRESSING WOUND CARE
}

\author{
I Dewa Ayu Rismayanti ${ }^{1}$, I Made Sundayana ${ }^{2}$, Putu Eka Pratama ${ }^{3}$ \\ Sekolah Tinggi Ilmu Kesehatan Buleleng ${ }^{1,2,3}$ \\ i.dewa.ayu.rismayanti-2019@fkp.unair.ac.id ${ }^{1}$
}

\begin{abstract}
ABSTRAK
Penelitian ini bertujuan untuk mengetahui pengaruh modern dressing terhadap penyembuhan luka diabetes mellitus grade 2 di Griya Utami Care Bali. Desain yang digunakan dalam penelitian adalah true experiment dengan pendekatan one group prepost test. Hasil penelitian menunjukkan bahwa rata-rata nilai post pada kelompok eksperimen sebesar 8,67 dengan standar deviasi 2,024, sedangkan pada kelompok kontrol diperoleh rata-rata nilai post adalah 10,60 dengan standar deviasi 2,874. Berdasarkan hasil uji statistik didapatkan nilai p-value 0,042 , berarti ada perbedaan yang signifikan rata-rata nilai post antara kelompok eksperimen dengan kelompok kontrol. Simpulan, terdapat pengaruh modern dressing terhadap penyembuhan luka diabetes mellitus grade 2 di Griya Utami care Bali.
\end{abstract}

Kata Kunci: Diabetes Mellitus, Luka Diabetes Grade 2, Modern Dressing

\section{ABSTRACT}

This study aims to determine the effect of modern dressings on wound healing of grade 2 diabetes mellitus at Griya Utami Care Bali. The design used in the study was a real experiment with a one-group pre-post test approach. The results showed that the experimental group's average post value was 8.67, with a standard deviation of 2.024 . In the control group, the average post value was 10.60, with a standard deviation of 2.874. Based on the results of statistical tests, it was found that the p-value was 0.042, meaning that there was a significant difference in the average post value between the experimental group and the control group. In conclusion, there is an effect of modern dressings on wound healing for grade 2 diabetes mellitus at Griya Utami care Bali.

Keywords: Diabetes Mellitus, Grade 2 Diabetes Wounds, Modern Dressing

\section{PENDAHULUAN}

Diabetes Mellitus adalah penyakit kronis yang ditandai dengan tingginya kadar gula darah akibat kurangnya produksi insulin (hormon yang mengatur glukosa darah), menurunnya kerja insulin, atau keduanya (Shrivastva et al., 2019). Diabetes Mellitus juga merupakan salah satu penyakit tidak menular yang banyak terjadi di dunia maupun di Indonesia. Secara global, Cina memiliki kasus diabetes dengan jumlah penderita diabetes tertinggi lebih dari 109 juta orang dewasa terkena dampaknya dan diikuti oleh negara muslim seperti Indonesia sebagai tujuh teratas dengan 10 juta orang dewasa terpengaruh pada 2015 (Cho et al., 2018; Setyawati et al., 2020). 
Menurut International Diabetes Federation (2019) ada 463 juta orang dewasa (usia 20-79 tahun) yang mengalami DM di dunia pada tahun 2019 dan pada tahun 2045 angkanya diperkirakan akan meningkat menjadi 700 juta (IDF, 2019). Insiden DM di Indonesia meningkat dari tahun 2013 sebesar 6,9\% menjadi 10,9\% pada tahun 2018. Prevalensi DM di Provinsi Bali juga meningkat, mulai dari 1,3\% pada tahun 2013 lalu meningkat menjadi 1,7\% pada 2018 (Kementrian Kesehatan Republik Indonesia, 2018).

Manajemen DM yang buruk dapat menyebabkan terjadinya komplikasi akut, salah satunya adalah gangguan neuropati yaitu berkurangnya sensasi di kaki dan sering dikaitkan luka pada kaki (Sudarman et al., 2020). Neuropati perifer menyebabkan hilangnya rangsangan pada kaki dan mempunyai resiko tinggi untuk terjadinya ulkus pada kaki (Azizah et al., 2019). Luka kronis sering terjadi pada penderita diabetes mellitus karena adanya gangguan dalam mekanisme penyembuhan luka. Luka pada pasien DM tersebut akan memiliki dampak besar terhadap morbiditas, mortalitas dan kualitas hidup pasien DM (Seidel et al., 2020).

Sekitar 15\% dari pasien DM mengalami komplikasi berupa luka pada kaki selama hidup mereka (Seidel et al., 2020). Apabila penanganan luka ini dilakukan secara terlambat maka akan memperburuk keadaan dan akan mengakibatkan jaringan di sekitar luka menjadi mati, dan harus dilakukan amputasi (Santoso, 2017). Bahkan sekitar 50\% -70\% dari kasus amputasi kaki bagian bawah disebabkan oleh diabetes (Seidel et al., 2020). Hal tersebut akan menjadi beban medis, sosial, dan ekonomi yang signifikan terhadap pasien dalam waktu dekat (Spampinato et al., 2020). Oleh karena itu, kebutuhan akan alternatif terapeutik perawatan luka pasien DM sangat dibutuhkan.

Luka akut maupun luka kronis, keduanya membutuhkan perawatan dan penanganan luka yang baik. Penatalaksanaan luka adalah tindakan perawatan luka yang mencakup semua elemen termasuk kontrol komorbid dan komplikasi yang dapat terjadi akibat luka tersebut. Rangkaian kegiatan tersebut antara lain membersihkan luka dan mengganti balutan (Mahyudin et al., 2020). Perawatan luka konvensional yang sering dilakukan dengan menggunakan tulle dan kain kasa membutuhkan waktu penyembuhan yang lama, terutama untuk luka kronis dengan komplikasi tertentu. Lama perawatan dan kunjungan yang dilakukan oleh tenaga medis yang perlu lebih sering akan berdampak pada biaya perawatan. Selain itu, dari segi kenyamanan, pasien yang dirawat dengan perban konvensional seringkali mengeluhkan nyeri saat dibalut karena lukanya cenderung menempel dengan balutan (Mahyudin et al., 2020).

Metode terbaru dalam mengelola luka pada DM adalah dengan merancang teknik new wound care. Prinsip penggunaan perawatan luka adalah mengelola kondisi luka yang lembab (Liu et al., 2019). Kelembaban luka yang dikelola dengan baik akan mempercepat proses penyembuhan. Area luka akan mudah mengecil dan tidak mudah terinfeksi. Penatalaksanaan masalah luka pada DM dapat dilakukan melalui perawatan menggunakan modern dressing (Delshad et al., 2017). Modern dressing diketahui juga dapat digunakan untuk mempercepat proses penyembuhan luka (Alfaqih et al., 2019).

Berdasarkan studi pendahuluan yang telah dilakukan melalui wawancara kepada 10 orang pasien penderita Diabetes Mellitus grade 2 di Griya Utami Care Bali, ditemukan sebanyak 5 orang yang lukanya membaik dan 5 orang yang lukanya masih masih dalam lingkup grade 2 . Penelitian tentang penyembuhan luka pada pasien DM sudah pernah dilakukan seperti perawatan luka berupa folyurethane foam dressing, namun pada penelitian ini berfokus pada penggunaan modern dressing, selain itu, teknik ini belum banyak dilakukan di Bali. 


\section{METODE PENELITIAN}

Jenis penelitian yang digunakan adalah kuantitatif dengan rancangan penelitian True Experiment pre-post group. Jumlah populasi sebanyak 40 orang. Teknik sampling yang digunakan dalam penelitian ini adalah non probability sampling dengan teknik total sampling. Kriteria inklusi dalam penelitian ini adalah pasien DM tipe 2 yang memiliki luka grade 2, pasien berusia 57-65 tahun, pasien bersedia menjadi responden, dan pasien kooperatif. Diperoleh besar sampel sebanyak 30 orang, sampel tersebut kemudian dibagi dalam dua kelompok yaitu 15 orang pada kelompok kontrol dan 15 orang pada kelompok eksperimen. Alat pengumpulan data yang digunakan dalam penelitian adalah kuesioner BJWAT (Bates Jansen Wound Assesment). Kuesioner ini digunakan untuk mengetahui ukuran luka, kedalaman, tepi luka, goa, tepi jaringan nekrosis, jumlah jaringan nekrosis, tipe eksudat, jumlah eksudat, warna kulit sekitar luka, jaringan yang edema, pengerasan jaringan tepi, jaringan granulasi, dan epitelisasi.

Tempat atau lokasi penelitian dilakukan di home care Griya Utami Care Bali Sukasada. Prosedur penelitian dimulai dengan menentukan jumlah sampel penelitian, lalu meminta responden menandatangani surat persetujuan sebagai responden, mengumpulkan data umum responden, selanjutnya melakukan pre-test untuk mengetahui keadaan luka sebelum diberikan modern dressing, dan yang terakhir melaksanakan pemberian modern dressing pada responden.

Data secara keseluruhan dianalisis dengan menggunakan program komputer yaitu SPSS meliputi analisis deskriptif univariat dan analisis bivariat. Adapun analisa statistik menggunakan uji independent $t$-test.

\section{HASIL PENELITIAN}

Tabel. 1

Data Demografis Jenis Kelamin dan Riwayat Pendidikan Responden Penelitian

\begin{tabular}{cccccc}
\hline \multirow{2}{*}{ Variabel } & \multirow{2}{*}{ Kategori } & \multicolumn{4}{c}{ Kelompok } \\
\cline { 3 - 6 } & & \multicolumn{2}{c}{ Eksperimen } & \multicolumn{2}{c}{ Kontrol } \\
\cline { 3 - 5 } & Laki-laki & 10 & 66,7 & 9 & 60 \\
\hline Jenis kelamin & Perempuan & 5 & 33,3 & 6 & 40 \\
\hline Riwayat Pendidikan & SMP & 11 & 73,3 & 9 & 60 \\
& SMA & 4 & 26,7 & 6 & 40 \\
\hline
\end{tabular}

Berdasarkan tabel 1 diketahui bahwa karakteristik responden berdasarkan jenis kelamin pada kelompok eksperimen didapatkan mayoritas laki-laki sebanyak 10 orang $(66,7 \%)$ dan pada kelompok kontrol didapatkan mayoritas laki-laki sebanyak 9 orang $(60 \%)$. Berdasarkan riwayat pendidikan pada kelompok eksperimen mayoritas memiliki riwayat pendidikan SMP sebanyak 11 orang $(73,3 \%)$ dan pada kelompok kontrol mayoritas memiliki riwayat pendidikan SMP sebanyak 9 orang (60\%).

Tabel. 2

Data Demografis Usia Responden Penelitian

\begin{tabular}{ccccccc}
\hline & Variabel & N & Rerata & Min & Maks & SD \\
\hline \multirow{2}{*}{ Usia } & Eksperimen & 15 & 60,07 & 57 & 65 & 1,944 \\
& Kontrol & 15 & 60,07 & 58 & 64 & 1,907 \\
\hline
\end{tabular}


Berdasarkan tabel 2 diketahui bahwa rentang usia responden pada kelompok eksperimen adalah 57 hingga 65 tahun. Sedangkan rentang usia responden pada kelompok kontrol 58-64 tahun.

Tabel. 3

Identifikasi Penyembuhan Luka Diabetes Mellitus Grade 2 Sebelum Diberikan Modern Dressing pada Kelompok Eksperimen

\begin{tabular}{ccc}
\hline Kategori & Frekuensi & Persentase (\%) \\
\hline Wound Generation tipe 1 (skor 7) & 1 & 6,7 \\
Wound Generation tipe 2 (skor 10) & 6 & 40,0 \\
Kematian Jaringan tipe 1 (skor 14) & 8 & 53,3 \\
\hline Total & 15 & 100 \\
\hline
\end{tabular}

Berdasarkan tabel 3 diketahui bahwa sebelum diberikan modern dressing pada kelompok eksperimen, frekuensi penyembuhan luka responden mayoritas responden masuk dalam kategori kematian jaringan tipe 1 yaitu 8 (53,3\%) responden.

Tabel. 4

Penyembuhan Luka Diabetes Mellitus Grade 2 Sebelum Diberikan Modern Dressing pada Kelompok Eksperimen.

\begin{tabular}{cccccc}
\hline $\begin{array}{c}\text { Pre Test Kelompok } \\
\text { Eksperimen }\end{array}$ & $\mathrm{N}$ & Rerata & Minimum & Maksimum & SD \\
\cline { 2 - 6 } & 15 & 13,27 & 9 & 16 & 2,086 \\
\hline
\end{tabular}

Berdasarkan tabel 4 diketahui bahwa rata-rata nilai penyembuhan luka sebelum diberikan intervensi pada kelompok eksperimen adalah 13,27 dengan standar deviasi 2,086 .

Tabel. 5

Identifikasi Penyembuhan Luka Diabetes Mellitus Grade 2 Sebelum Diberikan Modern Dressing pada Kelompok Kontrol

\begin{tabular}{ccc}
\hline Kategori & Frekuensi & Persentase $(\%)$ \\
\hline Wound Generation tipe 1 (skor 7-9) & 8 & 53,3 \\
Wound Generation tipe 2 (skor 10-12) & 4 & 26,7 \\
Kematian Jaringan tipe 1 (skor 14-15) & 3 & 20 \\
\hline Total & 15 & 100 \\
\hline
\end{tabular}

Berdasarkan tabel 5 diketahui bahwa sebelum diberikan modern dressing pada kelompok kontrol, frekuensi penyembuhan luka mayoritas responden masuk dalam kategoti Wound Generation tipe 1 yaitu sebanyak $8(53,3 \%)$ responden.

Tabel. 6

Identifikasi Penyembuhan Luka Diabetes Mellitus Grade 2 Sebelum Diberikan Modern Dressing pada Kelompok Kontrol

\begin{tabular}{cccccc}
\hline \multirow{2}{*}{$\begin{array}{c}\text { Pre-Test Kelompok } \\
\text { Kontrol }\end{array}$} & $\mathrm{N}$ & Rerata & Minimum & Maksimum & SD \\
\cline { 2 - 6 } & 15 & 10,13 & 7 & 15 & 2,669 \\
\hline
\end{tabular}


Berdasarkan tabel 6 diketahui bahwa rata-rata nilai penyembuhan luka sebelum diberikan intervensi pada kelompok kontrol adalah 10,13 dengan standar deviasi 2,669.

Tabel.7

Indentifikasi Penyembuhan Luka Diabetes Mellitus Grade 2

Setelah Diberikan Modern Dressing pada Kelompok Eksperimen.

\begin{tabular}{ccc}
\hline Kategori & Frekuensi & Persentase (\%) \\
\hline Wound Generation tipe 1 (skor 6-9) & 11 & 73,3 \\
Wound Generation tipe 2 (skor 10-13) & 4 & 26,7 \\
\hline Total & 15 & 100 \\
\hline
\end{tabular}

Berdasarkan tabel 7 diketahui bahwa setelah diberikan modern dressing pada kelompok eksperimen, frekuensi penyembuhan luka mayoritas responden masuk dalam kategoti Wound Generation tipe 1 yaitu sebanyak $11(73,3 \%)$ responden.

Tabel. 8

Penyembuhan Luka Diabetes Mellitus Grade 2 Setelah Diberikan Modern Dressing pada Kelompok Eksperimen

\begin{tabular}{cccccc}
\hline Post Test Kelompok & $\mathrm{N}$ & Rerata & Minimum & Maksimum & SD \\
\cline { 2 - 6 } Eksperimen & 15 & 8,67 & 6 & 13 & 2,024 \\
\hline
\end{tabular}

Berdasarkan tabel 8 diketahui bahwa rata-rata nilai penyembuhan luka setelah diberikan intervensi pada kelompok eksperimen adalah 8,67 dengan standar deviasi 2,024 .

Tabel. 9

Identifikasi Penyembuhan Luka Diabetes Mellitus Grade 2 Setelah Diberikan Modern Dressing pada Kelompok Kontrol

\begin{tabular}{ccc}
\hline Kategori & Frekuensi & Persentase (\%) \\
\hline Wound Generation tipe 1 (skor 6-9) & 7 & 46,6 \\
Wound Generation tipe 2 (skor 10-13) & 4 & 26,7 \\
Kematian Jaringan tipe 1 (skor 14-15) & 4 & 26,7 \\
\hline Total & 15 & 100 \\
\hline
\end{tabular}

Berdasarkan tabel 9 diketahui bahwa setelah diberikan modern dressing pada kelompok kontrol, frekuensi penyembuhan luka mayoritas responden masuk dalam kategoti wound generation tipe 1 yaitu sebanyak 7 (46,6\%) responden.

Tabel. 10

Identifikasi Penyembuhan Luka Diabetes Mellitus Grade 2 Setelah Diberikan Modern Dressing pada Kelompok Kontrol

\begin{tabular}{cccccc}
\hline \multirow{2}{*}{$\begin{array}{c}\text { Pre test Kelompok } \\
\text { Kontrol }\end{array}$} & $\mathrm{N}$ & Rerata & Minimum & Maksimum & SD \\
\cline { 2 - 6 } & 15 & 10,60 & 7 & 15 & 2,874 \\
\hline
\end{tabular}

Berdasarkan tabel 10 diketahui bahwa rata-rata nilai penyembuhan luka setelah diberikan intervensi pada kelompok kontrol adalah 10,60 dengan standar deviasi 2,874. 
Tabel. 11

Identifikasi Perbedaan Penyembuhan Luka Diabetes Mellitus Grade 2 Sebelum dan Setelah Diberikan Modern Dressing.

\begin{tabular}{|c|c|c|c|c|c|}
\hline \multirow[b]{2}{*}{ Variabe } & & \multirow[b]{2}{*}{$\mathrm{N}$} & \multirow[b]{2}{*}{ Mean \pm SD } & \multicolumn{2}{|c|}{ Paired Differences } \\
\hline & & & & $\begin{array}{c}\text { Perbedaan } \\
(\text { Mean } \pm \text { SD })\end{array}$ & $P$ \\
\hline Kelompok & Pre-test & \multirow[t]{2}{*}{15} & $13,27 \pm 2,086$ & \multirow{2}{*}{$4,600 \pm 2,089$} & \multirow{2}{*}{0,000} \\
\hline Eksperimen & Post-test & & $8,67 \pm 2,024$ & & \\
\hline Kelompok Kontrol & Pre-test & 15 & $10,13 \pm 2,669$ & $-0,467 \pm 3,701$ & 0,633 \\
\hline
\end{tabular}

Berdasarkan tabel 11 diketahui bahwa terdapat perbedaan data sebelum dan setelah diberikan modern dressing pada kelompok eksperimen dengan p-value 0,000 $(\alpha \leq 0,05)$. Artinya, ada perbedaan yang signifikan dari penyembuhan luka Diabetes Mellitus grade 2 sebelum dan setelah diberikan modern dressing. P-Value pada kelompok kontrol adalah 0,633 berarti nilai $\alpha>0,05$ sehingga tidak ada perbedaan penyembuhan luka diabetes mellitus grade 2 sebelum dan setelah diberikan modern dressing pada kelompok kontrol.

Tabel. 12

Analisis Pengaruh Modern Dressing terhadap Penyembuhan Luka Diabetes Mellitus Grade 2 pada Kelompok Eksperimen dan Kontrol di Griya Utami Care Bali

\begin{tabular}{lccccccc}
\hline \multicolumn{7}{c}{ Uji Independent t-test } \\
\hline & $\mathrm{N}$ & Kelompok & Mean & SD & SE & $P$ \\
\hline Modern & \multirow{2}{*}{15} & Eksperimen & 8,67 & 2,024 & 0,523 & \multirow{2}{*}{ Sig. } & 0,042 \\
Dressing & & Kontrol & 10,60 & 2,874 & 0,742 & & \\
\hline
\end{tabular}

Berdasarkan tabel 12 diketahui bahwa rata-rata nilai post pada kelompok eksperimen 8,67 dengan standar deviasi 2,024, sedangkan untuk kelompok kontrol ratarata nilai post adalah 10,60 dengan standar deviasi 2,874. Hasil uji statistik didapatkan nilai $p$-value 0,042 , berarti ada perbedaan yang signifikan rata-rata nilai post antara kelompok eksperimen dengan kelompok kontrol.

\section{PEMBAHASAN}

Berdasarkan hasil penelitian yang telah dilakukan, sebelum diberikan modern dressing dengan metode foam dressing pada kelompok eksperimen, diketahui bahwa frekuensi penyembuhan luka mayoritas responden termasuk dalam kategori kematian jaringan tipe 1. Hasil penelitian pre-test pada kelompok kontrol didapatkan hasil frekuensi penyembuhan luka mayoritas responden masuk dalam kategori wound dressing tipe 1.

Hasil penelitian ini sejalan dengan Edmonds et al., (2018) yang menyatakan bahwa penyembuhan permukaan luka pada kelompok intervensi dengan modern dressing lebih cepat dibandingkan pada kelompok kontrol yang mencapai 20 minggu. Berdasarkan hasil systematic review yang dilakukan oleh Vas et al., (2020) diketahui dari berbagi penelitian didapatkan hasil bahwa jenis modern dressing memiliki tingkat efektivitas lebih tinggi daripada conventional dressing. Terutama apabila pemberian modern dressing dikombinasikan dengan berbagai obat topikal, atau beberapa produk yang mengandung membran plasma. Namun, kecepatan penyembuhan luka juga 
bergantung pada jenis keparahan luka, durasi luka dan durasi perawatan luka yang diberikan.

Hasil lain dari penelitian ini adalah pada gambaran penyembuhan luka diabetes mellitus grade 2 pada kelompok eksperimen menunjukkan bahwa frekuensi penyembuhan luka mayoritas responden masuk dalam kategori wound generation tipe 1. Gambaran Penyembuhan luka diabetes mellitus grade 2 pada kelompok kontrol setelah diberikan modern dressing bahwa frekuensi penyembuhan luka mayoritas responden masuk dalam kategori wound generation tipe 1. Menurut hasil penelitian (Ose et al., 2018), didapatkan hasil bahwa rata-rata efektifitas pada kelompok perawatan luka dengan menggunakan teknik wet-dry sebesar $2,33 \%$ sedangkan pada penyembuhan luka moist wound healing rata-rata $1,40 \%$.

Hasil uji paired $t$ test menunjukkan bahwa ada perbedaan yang signifikan penyembuhan luka diabetes mellitus grade 2 sebelum dan setelah diberikan modern dressing. Sedangkan pada kelompok kontrol tidak ada perbedaan penyembuhan luka diabetes mellitus grade 2 sebelum dan setelah diberikan modern dressing. Pada umumnya luka pada pasien diabetes mellitus bersifat heterogen, jadi tidak ada balutan tunggal yang ideal untuk semua jenis luka. Secara umum disepakati bahwa tujuan pembalutan harus menciptakan lingkungan lembab yang mendorong granulasi, proses autolitik, angiogenesis, dan migrasi sel epidermis yang lebih cepat melintasi dasar luka. Balutan yang dipilih juga harus sesuai untuk mengelola eksudat luka berlebih (Everett \& Mathioudakis, 2018).

Sekitar 15\% dari pasien DM mengalami komplikasi berupa luka pada kaki selama hidup mereka (Seidel et al., 2020). Apabila penanganan luka ini dilakukan secara terlambat maka akan memperburuk keadaan dan akan mengakibatkan jaringan di sekitar luka menjadi mati, dan harus dilakukan amputasi (Santoso, 2017). Bahkan sekitar 50\% -70\% dari kasus amputasi kaki bagian bawah disebabkan oleh diabetes (Seidel et al., 2020). Hal tersebut akan menjadi beban medis, sosial, dan ekonomi yang signifikan terhadap pasien dalam waktu dekat (Spampinato et al., 2020). Oleh karena itu, kebutuhan akan alternatif terapeutik untuk perawatan luka pada pasien DM sangat dibutuhkan.

\section{SIMPULAN}

Ada pengaruh modern dressing terhadap efektifitas penyembuhan luka grade 2 pada pasien diabetes mellitus pada kelompok Eksperimen, sedangkan pada kelompok kontrol tidak ada pengaruh antara modern dressing terhadap efektifitas penyembuhan luka grade 2 pada pasien diabetes mellitus.

\section{SARAN}

Penelitian ini diharapkan dapat dijadikan acuan dalam pengembangan intervensi keperawatan khususnya yang berhubungan dengan perawatan luka pada pasien diabetes mellitus yang menggunakan metode modern dressing dalam membantu percepatan penyembuhan luka. Selain itu, hasil penelitian ini dapat digunakan sebagai informasi bagi tempat pelayanan kesehatan guna meningkatkan pelayanan khususnya pelayanan di Griya Utami Care Bali, sehingga pelayanan kesehatan dapat lebih optimal.

Bagi penelitian selanjutnya disarankan untuk mengambil sampel dengan subyek penelitian yang bervariasi seperti usia middle age (45-50 tahun), (60-74 tahun), dan lanjut usia tua ialah usia (75-90 tahun), dengan jenis kelamin laki-laki dan perempuan, 
bagi penelitian selanjutnya disarankan untuk selalu memonitor kadar gula darah klien untuk memaksimalisasi hasil penelitian.

\section{DAFTAR PUSTAKA}

Alfaqih, M. R., Sinawang, G. W., Faizah, R., \& Hermanto, A. (2019). The Management of Diabetic Foot Ulcers Using the Wound Treatment Techniques of Modern Dressing: A Systematic Review. Jurnal Ners, 14(3), 177-181. DOI: 10.20473/jn.v14i3.17016

Azizah, N., Intan, I., Tulak, D., Kurniawan, M. A., \& Afelya, T. I. (2019). Diabetic Foot Ulcer Treatment Post AutoAmputation Digiti Pedis Sinistra: Case Study. Indonesian Contemporary Nursing Journal, 4(1), 27-37. DOI: 10.20956/icon.v4i1.5595

Delshad, E., Tavakkoli-Kakhki, M., \& Motavasselian, M. (2017). Successful Repair of Diabetic Foot Ulcer with Honey-Based Treatment: A Case Report. Iranian Red Crescent Medical Journal, 19(3). DOI: 10.5812/ircmj.41939

Edmonds, M., Lázaro-Martínez, J. L., Alfayate-García, J. M., Martini, J., Petit, J.-M., Rayman, G., Lobmann, R., Uccioli, L., Sauvadet, A., \& Bohbot, S. (2018). Sucrose Octasulfate Dressing Versus Control Dressing in Patients with Neuroischaemic Diabetic Foot Ulcers (Explorer): An International, Multicentre, Double-Blind, Randomised, Controlled Trial. The Lancet Diabetes \& Endocrinology, 6(3), 186-196. DOI: 10.1016/S2213-8587(17)30438-2

Everett, E., \& Mathioudakis, N. (2018). Update on Management of Diabetic Foot Ulcers. Annals of the New York Academy of Sciences, 1411(1), 153. DOI: 10.1111/nyas. 13569

IDF. (2019). IDF Diabetes Atlas 9th edition 2019. International Diabetes Federation Diabetes Atlas, Ninth Edition, 1-176, https://www.diabetesatlas.org/en/

Kementrian Kesehatan Republik Indonesia. (2018). Profil Kesehatan Indonesia Tahun 2018. Jakarta: Kementerian Kesehatan RI, 170-173

Liu, Y., Zhou, S., Gao, Y., \& Zhai, Y. (2019). Electrospun Nanofibers as a Wound Dressing for Treating Diabetic Foot Ulcer. Asian Journal of Pharmaceutical Sciences, 14(2), 130-143. DOI: 10.1016/j.ajps.2018.04.004

Mahyudin, F., Edward, M., Basuki, M. H., Basrewan, Y., \& Rahman, A. (2020). Modern and Classic Wound Dressing Comparison in Wound Healing, Comfort and Cost. Jurnal Ners, 15(1), 31. DOI: 10.20473/jn.v15i1.16597

Ose, M. I., Utami, P. A., \& Damayanti, A. (2018). Efektivitas Perawatan Luka Teknik Balutan Wet-Dry dan Moist Wound Healing pada Penyembuhan Ulkus Diabetik. Journal of Borneo Holistic Health, 1(1), 101-112. http://jurnal.borneo.ac.id/index.php/borticalth/article/view/401/263

Santoso, W. (2017). Effectiveness Wound Care Using Modern Dressing Method to Diabetic Wound Healing Process of Patient with Diabetes Mellitus. International Journal of Nursing and Midwifery Science (IJNMS), 1(2), 172-181. DOI: https://doi.org/10.29082/IJNMS/2017/Vol1.Iss2.68

Seidel, D., Storck, M., Lawall, H., Wozniak, G., Mauckner, P., Hochlenert, D., WetzelRoth, W., Sondern, K., Hahn, M., \& Rothenaicher, G. (2020). Negative Pressure Wound Therapy Compared with Standard Moist Wound Care on Diabetic Foot Ulcers in Real-Life Clinical Practice: Results of the German DiaFu-RCT. BMJ Open, 10(3), e026345. DOI: 10.1136/bmjopen-2018-026345 
Setyawati, A. D., Ngo, T. H. L., Padila, P., \& Andri, J. (2020). Obesity and Heredity for Diabetes Mellitus among Elderly. JOSING: Journal of Nursing and Health, 1(1), 26-31. https://doi.org/https://doi.org/https://doi.org/10.31539/josing.v1i1.1149

Shrivastva, A., Phadnis, S., Rao, K., \& Gore, M. (2019). A Study on Knowledge and Self-Care Practices about Diabetes Mellitus among Patients with Type 2 Diabetes Mellitus attending selected tertiary healthcare facilities in coastal Karnataka. Clinical Epidemiology and Global Health, 8(3), 689-692. DOI: 10.1016/j.cegh.2020.01.003

Spampinato, S. F., Caruso, G. I., De Pasquale, R., Sortino, M. A., \& Merlo, S. (2020). The Treatment of Impaired Wound Healing in Diabetes: Looking among Old Drugs. Pharmaceuticals, 13(4), 60. DOI: 10.3390/ph13040060

Sudarman, S., Asfar, A., \& Amir, H. (2020). Modern Dressing Wound Care Effective Healing Diabetic Wounds In Isam Cahaya Holistic Care. Jurnal Ipteks Terapan, 14(2), 138-145. DOI : http://doi.org/10.22216/jit.2020.v14i2.5384

Vas, P., Rayman, G., Dhatariya, K., Driver, V., Hartemann, A., Londahl, M., Piaggesi, A., Apelqvist, J., Attinger, C., \& Game, F. (2020). Effectiveness of interventions to enhance healing of chronic foot ulcers in diabetes: a systematic review. Diabetes/Metabolism Research and Reviews, 36(S1), e3284. DOI: 10.1002/dmrr.3284 